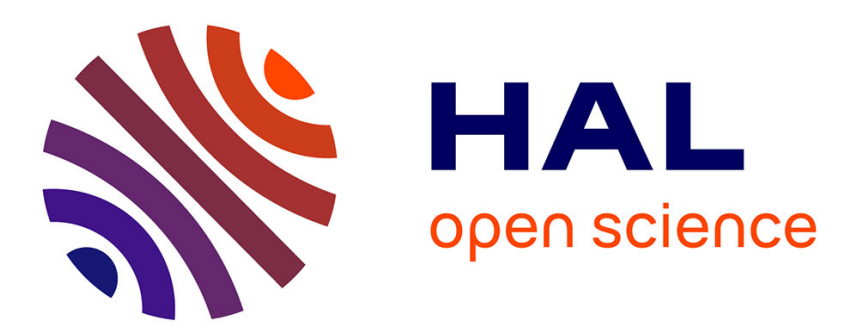

\title{
Use of ion beam analysis techniques to characterise iron corrosion under water radiolysis
}

S. Lapuerta, N. Moncoffre, N. Millard-Pinard, E. Mendes, C. Corbel, D.

Crusset

\section{- To cite this version:}

S. Lapuerta, N. Moncoffre, N. Millard-Pinard, E. Mendes, C. Corbel, et al.. Use of ion beam analysis techniques to characterise iron corrosion under water radiolysis. Eighth European Conference on Accelerators in Applied Research and Technology (ECAART-8), Sep 2004, Paris, France. pp.288-292, 10.1016/j.nimb.2005.06.131 。 in2p3-00024644

HAL Id: in2p3-00024644

https://hal.in2p3.fr/in2p3-00024644

Submitted on 22 Sep 2005

HAL is a multi-disciplinary open access archive for the deposit and dissemination of scientific research documents, whether they are published or not. The documents may come from teaching and research institutions in France or abroad, or from public or private research centers.
L'archive ouverte pluridisciplinaire HAL, est destinée au dépôt et à la diffusion de documents scientifiques de niveau recherche, publiés ou non, émanant des établissements d'enseignement et de recherche français ou étrangers, des laboratoires publics ou privés. 


\title{
Use of ion beam analysis techniques to characterise iron corrosion under water radiolysis
}

\author{
S. Lapuerta ${ }^{\mathrm{a}, \mathrm{b}}$, N. Moncoffre ${ }^{\mathrm{a}}$, N. Millard-Pinard ${ }^{\mathrm{a}}$, E. Mendes $^{\mathrm{c}}, \mathrm{C}^{\mathrm{C}}$ Corbel $^{\mathrm{c}}$, D. Crusset ${ }^{\mathrm{b}}$. \\ a Institut de Physique Nucléaire de Lyon , 4, rue Enrico Fermi , 69622 Villeurbanne cedex, \\ France, \\ b ANDRA, Parc de la Croix Blanche 1-7 rue Jean Monnet, F-92298 Châtenay-Malabry \\ Cedex, France \\ c Commissariat à l’Energie Atomique, CEA-Saclay, DSM/DRECAM/SCM/Laboratoire CEA \\ de radiolyse, Bat. 546, F-91191 Gif-sur-Yvette, France
}

\begin{abstract}
The aim of this paper is to study the effect of water radiolysis under $12 \mathrm{MeV}$ proton irradiation on the corrosion behaviour of pure iron. Oxygen and hydrogen playing a crucial role during the corrosion process have been specifically investigated. Heavy desaerated water (enriched at $99.9 \%$ in D) was also used to determine the origin of hydrogen at the iron surface. Proton irradiations were performed at the CERI cyclotron in Orléans. Both sides of the Fe foil (respectively in contact with air and with water) were analysed with ion beam techniques: Alpha Rutherford Backscattering Spectrometry was used to profile oxygen, Elastic Recoil Detection analysis has allowed to profile hydrogen. The use of $\mathrm{D}_{2} \mathrm{O}$ gives evidence that the hydrogen concentration present on the water face could originate from wet air. In addition, in case of the aerated deionised $\mathrm{H}_{2} \mathrm{O}$ media, it is shown that the irradiation
\end{abstract}


process induces a strong corrosion. Scanning electron microscopy experiments confirm the formation of oxide precipitates.

PACS: 61.72.Ss, 61.80.Jh, 61.82.Bj

Keywords: Iron corrosion, radiolysis, ion beam analysis

Corresponding author:

S.Lapuerta

Institut de Physique Nucléaire de Lyon

4 rue Enrico Fermi

69622 Villeurbanne Cedex

France

e-mail: lapuerta@ipnl.in2p3.fr

Phone : +33472431063

Fax: +33 472448004 


\section{Introduction}

In the perspective of a geological disposal, high level nuclear wastes will be embedded in stainless steel. The second barrier will be very likely a low alloyed carbon steel overpack. It is assumed that, progressively, water will penetrate the geological site and after some hundred years, overpacks will be in contact with water and submitted to $\gamma$ irradiation. Because of the radioactive environment, water radiolysis will occur. This radiolysis produces both molecular $\left(\mathrm{H}_{2} \mathrm{O}_{2}, \mathrm{H}_{2}\right)$ and radical products $\left(\mathrm{OH}^{\bullet}, \mathrm{O}_{2}^{-\bullet}, \mathrm{HO}_{2}^{\bullet}, \mathrm{e}^{-}\right.$aq, $\left.\mathrm{H}^{\bullet}\right)$ which could accelerate the corrosion process. Lots of works deal with the comparison of the radiolysis product primary yields induced by either $\gamma$, electron or proton irradiations [1]. Moreover these yields have been estimated as function of LET (Linear Energy Transfer) by Monte Carlo simulations [2]. In this context, we propose a fundamental study to better understand the corrosion mechanisms of pure iron, considered as a model material, under proton irradiation. We have chosen proton irradiation for two main reasons. First, the protons produce a high ionisation density correlated with a high LET compared to $\gamma$ irradiation and it has been shown that water radiolysis strongly depends on the LET value $[3,4]$. Second, the beam energy control allows to study the corrosion process precisely at the iron/water interface. Several papers have put in evidence enhanced corrosion under charged particle irradiations in different materials: ceramics [5], zircaloy [6] and other metals [7]. Few works have been done on mild steels or pure iron. Burns [8] shows that, under $\gamma$ irradiation, an increase of the $\mathrm{H}_{2}$ production occurs and he proposes specific reactions to explain the strong observed corrosion effect.

In this paper, we will study the corrosion of pure iron in contact with water under $12 \mathrm{MeV}$ proton irradiation. In order to follow the iron surface evolution, an Eu marker introduced by ion implantation is used and analysed by Rutherford Backscattering Spectrometry (RBS). In addition, oxygen and hydrogen profiles are determined by ion beam analysis. Two types of experiments were realised with 2 different water media : aerated deionized water $\left(\mathrm{H}_{2} \mathrm{O}\right)$ and 
heavy water $\left(\mathrm{D}_{2} \mathrm{O}\right)$ packaged under argon. By the comparison of these two experiments, we have been able to determine the origin of hydrogen at the iron/water interface and the influence of dissolved species in water.

\section{Experimental:}

The studied material is pure iron (99.995\%). The samples are $250 \mu \mathrm{m}$ thick discs with a $8 \mathrm{~mm}$ diameter. Since the iron disc thickness is very thin, only the iron surface in contact with water is mechanically polished with a $3 \mu \mathrm{m}$ diamond paste. The measured rugosity is consequently of $50 \mathrm{~nm}$ on the non polished side and $5 \mathrm{~nm}$ on the polished one.

Samples are Eu implanted on the polished face at an energy of $300 \mathrm{keV}$ and a fluence of $5 \times 10^{15}$ at $\mathrm{cm}^{-2}$. These implantation conditions correspond to a $30 \mathrm{~nm}$ range given by the SRIM simulation [9] and an Eu concentration maximum value of 1.1 at\%.

The irradiation experiments are performed with the CERI (Centre d'Etudes et de Recherches par Irradiation) cyclotron at Orleans, which delivers a $12 \mathrm{MeV}$ proton beam. The external proton beam enters the irradiation cell $(\mathrm{V}=20 \mathrm{~mL})$ through the $250 \mu \mathrm{m}$ thick iron foil and emerges into water with a $4.5 \mathrm{MeV}$ energy where it finally stops after a $290 \mu \mathrm{m}$ range. Figure 1 presents a schematic drawing of the irradiation set up. The LET at this energy is equal to 8.8 $\mathrm{eV} \mathrm{nm}^{-1}$ which is much higher than that induced by $\gamma$ irradiation $\left(0.2 \mathrm{eV} \mathrm{nm}^{-1}\right)$. Samples are irradiated with a $30 \mathrm{nA}$ beam intensity. This intensity, which corresponds to an irradiation flux of $6.7 \times 10^{11} \mathrm{p} \mathrm{cm}^{-2} \mathrm{~s}^{-1}$, is set constant and measured carefully both by a Faraday cup and an ionisation chamber during the experiments. The irradiation time is equal to 2 hours which corresponds to a fluence $\Phi$ of $4.8 \times 10^{15} \mathrm{p} \mathrm{cm}^{-2}$.

In order to study the irradiation effect, it is of primary importance to compare a non irradiated sample and an irradiated one. For that reason, a sample preparation procedure has been defined to ensure that all the studied samples present the same surface state before irradiation. 
Therefore, two samples are systematically submitted to the same treatment: the polished side is put in contact with $\mathrm{H}_{2} \mathrm{O}$ during 12 hours, then, the cell water is changed and only one sample is irradiated during 2 hours. The same ion beam analysis is performed on each sample. We will call the non irradiated sample, $\phi=0$ (blank) and the irradiated one, $\phi=4.8 \times 10^{15} \mathrm{p}$ $\mathrm{cm}^{-2}$.

Ion beam analysis was performed using the $4 \mathrm{MV}$ Van de Graaff accelerator of the "Institut de Physique Nucléaire” of Lyon. RBS analysis was performed at a $172^{\circ}$ detection angle with 1.7 or $2 \mathrm{MeV} \alpha$ particles whereas for the ERDA analysis, which allows to determine the hydrogen profiles, $\mathrm{H}$ recoil was induced by $1.7 \mathrm{MeV} \alpha$ particles. The detected recoil protons have then a $816 \mathrm{keV}$ energy. The incident angle on the target is $15^{\circ}$, the detection angle is $30^{\circ}$. A $6.5 \mu \mathrm{m}$ thick mylar absorber is placed in front of the Si detector to stop backscattered $\alpha$ particles. In such conditions, the depth resolution is close to $20 \mathrm{~nm}$ in iron.

The SIMNRA program was used to simulate the energy spectra obtained both by RBS and ERDA so as to determine the atomic concentration profiles of europium, oxygen and hydrogen. For a given sample analysed by RBS and ERDA, the analysis was done by iteration, taking always into account, in the simulations files, the europium, oxygen and hydrogen concentrations.

\section{Results}

3.1 Evidence of iron corrosion using RBS analysis

Figure 2 displays RBS spectra obtained at the Fe/water interface for the two $\mathrm{D}_{2} \mathrm{O}$ (fig.2a) and $\mathrm{H}_{2} \mathrm{O}$ (fig. 2b) water media. On each figure, a comparison is given of experiments performed before and after irradiation. A focus on the Eu signals is also given in figures 2a and 2b.

The main result is a very strong decrease of the iron signal for the sample irradiated in light water (fig. 2b) which is characteristic of a deep oxidation. As well, we observe a total loss of 
Eu after irradiation in $\mathrm{H}_{2} \mathrm{O}$. Taking into account the Eu range, it corresponds to at least a 60 $\mathrm{nm}$ thick iron loss. The rust deposit observed in the cell after irradiation confirms this iron release. For irradiation in $\mathrm{D}_{2} \mathrm{O}$, the iron loss is inferior to $5 \%$ (fig. 2a) but a $5 \mathrm{keV}$ shift in the Eu distribution is observed which could be attributed to a slight iron oxidation.

The oxygen concentration profiles are deduced from the RBS iron signal analysis taking into account the europium concentration deduced from RBS and the hydrogen concentration deduced from ERDA. The fitted oxygen distributions at the $\mathrm{Fe} / \mathrm{D}_{2} \mathrm{O}$ interface (simulation fit from fig. 2a) and at the $\mathrm{Fe} / \mathrm{H}_{2} \mathrm{O}$ interface (simulation fit from fig.2b), are displayed in figure 3. They put in evidence that after irradiation in heavy water a slight oxidation (35 at. \% of oxygen at the surface) occurs on a depth roughly equal to $160 \mathrm{~nm}$. On the other hand, for the sample irradiated in $\mathrm{H}_{2} \mathrm{O}$ the strong oxidation (60 at. \%) concerns the whole analysed surface (nearly $1000 \mathrm{~nm}$ ).

A Scanning Electron Microscopy (SEM) image has also shown that the surface is heterogeneous with the presence of oxide precipitates which can be $2 \mu \mathrm{m}$ thick. Moreover, a $\mathrm{X}$ microprobe analysis allows to determine two oxide stoichiometries: $\mathrm{O} / \mathrm{Fe}=0.96$ and $\mathrm{O} / \mathrm{Fe}=1.52$, the first one being close to $\mathrm{FeO}$ and the other one close to $\mathrm{FeOOH}$ or $\mathrm{Fe}_{3} \mathrm{O}_{4}$.

3.2 Evidence of hydrogen enhanced migration under irradiation using ERDA analysis:

The hydrogen analysis was performed at the $\mathrm{Fe} / \mathrm{H}_{2} \mathrm{O}$ and $\mathrm{Fe} / \mathrm{D}_{2} \mathrm{O}$ interfaces and the experimental spectra are displayed in figure 4. The corresponding hydrogen concentration profiles are presented in figure 5. We observe that, for $\phi=0$ (fig. 5a), hydrogen is present at the very near surface on about $30 \mathrm{~nm}$, while for the irradiated samples, hydrogen is present deeper in the bulk at a concentration level of about 10 at. \% even in $\mathrm{D}_{2} \mathrm{O}$. It was unexpected to observe hydrogen at the $\mathrm{Fe} / \mathrm{D}_{2} \mathrm{O}$ interface and in order to determine its origin, the air/Fe interfaces were also analysed. Figure $5 \mathrm{~b}$ represents the $\mathrm{H}$ profiles at the air/Fe interface for 
different samples: virgin iron (kept in dry atmosphere), blank ( $\phi=0$ but submitted to a wet atmosphere characterised by a relative humidity of about $50 \%$ during 12 hours) and an irradiated sample. It appears that in virgin iron, the hydrogen contamination is very superficial. In contrast, the blank sample has a significant amount of hydrogen over an important depth in comparison with the air/Fe interface on the virgin sample. It puts forwards the importance of the atmosphere relative humidity on the iron surface composition [10]. The hydrogen concentration in the blank sample is comparable to the one of the irradiated sample. Since the surface rugosity has been measured equal to $50 \mathrm{~nm}, \mathrm{H}$ profiles on that thickness cannot be compared. However, beyond $50 \mathrm{~nm}$, hydrogen is equally distributed at a mean concentration of 10 at. \%. This result confirms that hydrogen comes from the wet air.

\section{Discussion}

These experiments have shown that the iron corrosion in aerated water was faster than in desaerated one. We have shown using the Eu marker that, at least, a $60 \mathrm{~nm}$ iron loss had occurred in aerated water. It is related to a strong oxidation at the $\mathrm{Fe} / \mathrm{H}_{2} \mathrm{O}$ interface observed on the whole analysed depth (nearly $1 \mu \mathrm{m}$ ). This result is in agreement with the work of Burns [8] who has demonstrated that corrosion under irradiation is dependent on the presence of dissolved species in water $\left(\mathrm{N}_{2}, \mathrm{O}_{2}\right)$ giving rise to very reactive radicals. As well, Petrik [11] notices the increase of the corrosion rate of copper as a function of the nitrite and nitrate ion concentration.

Concerning the $\mathrm{H}$ analysis, before irradiation, the blank sample indicates the presence of $\mathrm{H}$ on the air/Fe face but not on the Fe/water one. After irradiation, $\mathrm{H}$ is observed whatever the water types at a concentration of meanly 10 at.\%. Thus, this 2 hour irradiation process enhances the $\mathrm{H}$ diffusion through the entire iron foil. A schematic representation of the hydrogen distribution in the iron foil is given in figure 6 to synthesise these results. 
Considering the very high hydrogen thermal diffusion coefficient ranging between $10^{-4}$ and $10^{-8} \mathrm{~cm}^{2} \mathrm{~s}^{-1}$ at $25^{\circ} \mathrm{C}[12,13]$, we can make the hypothesis that hydrogen has diffused from the wet air/Fe interface to the Fe/water one. Further experiments using the $\mathrm{D}\left({ }^{3} \mathrm{He}, \alpha\right) \mathrm{p}$ nuclear reaction will allow to check this explanation.

\section{Acknowledgement}

The authors are very grateful to N. Bérerd, N. Chevarier and H. Jaffrézic for very helpful discussions.

\section{References}

[1] Y. Frongillo, T. Goulet, M. J Fraser, V. Cobut, J. P. Patau, J.P. Jay-Gerin, Radiat. Phys. Chem., 51, 3, (1998), 245.

[2] J. Meesungnoen, J. P Jay-Gerin, A. Filali-Mouhim, S. Mankhetkorn, Can. J. Chem., 80, (2002), 68.

[3] W. G. Burns, H. E. Sims, J. Chem. Soc., Faraday Trans. 1, 77, (1981), 2803.

[4] V. Wasselin-Trupin, G. Baldacchino, S. Bouffard, B. Hickel, Rad. Physics and Chem.65 (2002) 53.

[5] C. Corbel, G. Sattonnay, J. F. Lucchini, C. Ardois, M. F. Barthe, F. Huet, P. Dehaudt, B. Hickel, C. Jegou, Nucl. Instr. And Meth. in Phys. Res. B 179 (2001) 225.

[6] W. G. Burns, P. B. Moore, Rad. Effects, (30) 4 (1976) 233.

[7] R. S. Lillard, D. L. Pile, D. P. Butt, J. of Nucl. Materials, 278 (2000) 277.

[8] W. G. Burns, W. R. Marsh, W. S. Walters, Rad. Phys. Chem., 21, n³, (1983) 259. 
[9] J. F. Ziegler, J. P. Biersack, U. Littmark; The stopping and range of ions in solids; Pergamon press, New York; 1985.

[10] S.Hoerlé, F. Mazaudier, Ph. Dillmann, G. Santarini, Corrosion Science, 46 (2004) 14311465

[11] N. G. Petrik, M. N. Petrov, V. G. Fomin, High Energy Chem., vol. 31, n5 (1997) 308.

[12] H. Peisl, Hydrogen in metal I ed. G. Alefeld and J. Volkl, Springer Verlag (1978).

[13] R. Nishimura, D. Shiraishi, Y. Maeda, Corrosion science, 46 (2004) 225. 


\section{Figure captions}

Figure 1 : Schematic representation of the irradiation set up for iron leaching under proton beam.

Figure 2 : RBS spectra of the Fe/water interface obtained before and after irradiation : (a) leaching in deasaerated $\mathrm{D}_{2} \mathrm{O}$, (b) leaching in aerated $\mathrm{H}_{2} \mathrm{O}$. The analysis energies are respectively $2 \mathrm{MeV}$ (a) and $1.7 \mathrm{MeV}$ (b). A loop on the europium signals is given in inset. The full lines represent the simulated curves.

Figure 3: Oxygen profiles deduced from RBS measurements on $\mathrm{Fe} / \mathrm{D}_{2} \mathrm{O}$ and $\mathrm{Fe} / \mathrm{H}_{2} \mathrm{O}$ interfaces after 2 hour proton irradiation.

Figure 4: ERDA experimental profiles obtained on the Fe/water interface (a) and air/Fe interface (b) on different samples. The full lines represent the simulated curves.

Figure 5 : Hydrogen profiles deduced from ERDA measurements (a) on $\mathrm{Fe} / \mathrm{D}_{2} \mathrm{O}$ and $\mathrm{Fe} / \mathrm{H}_{2} \mathrm{O}$ interfaces after 2 hour proton irradiation. For comparison the non irradiated sample after 2 hour leaching is presented $(\Phi=0)$. The iron loss thickness is schematised by the dashed zone. (b) on Air/Fe interfaces after 2 hour proton irradiation. For comparison, the spectra of the non irradiated sample after 2 hour leaching in $\mathrm{D}_{2} \mathrm{O}(\Phi=0)$ and of the virgin iron, are presented.

Figure 6 : Schematic representation of the hydrogen distribution evolution in the iron foil. 
Figure 1

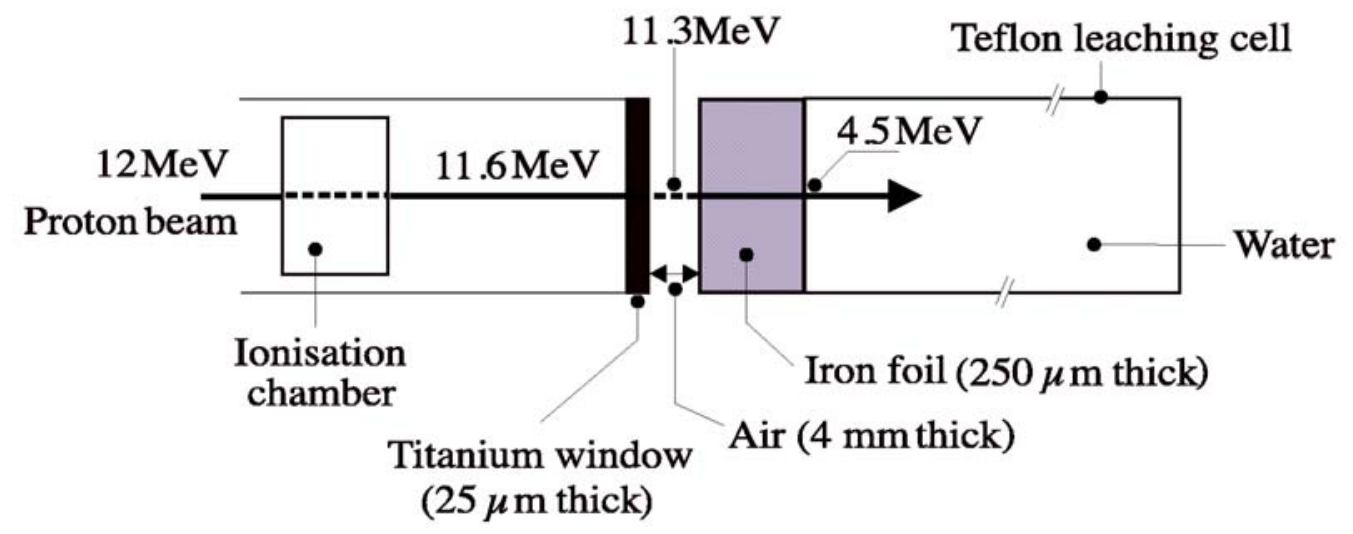


Figure2

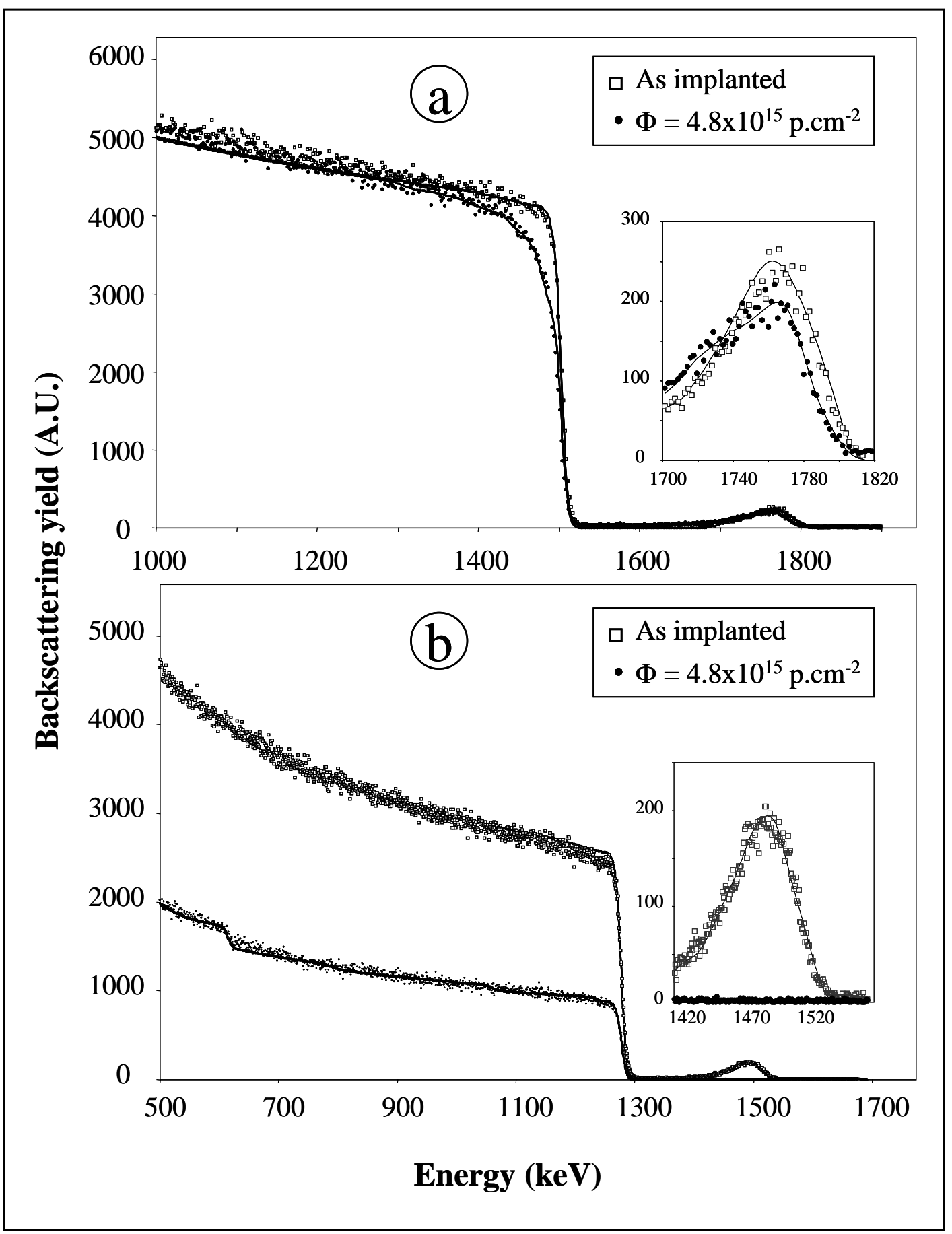


Figure 3

\section{Depth (nm)}

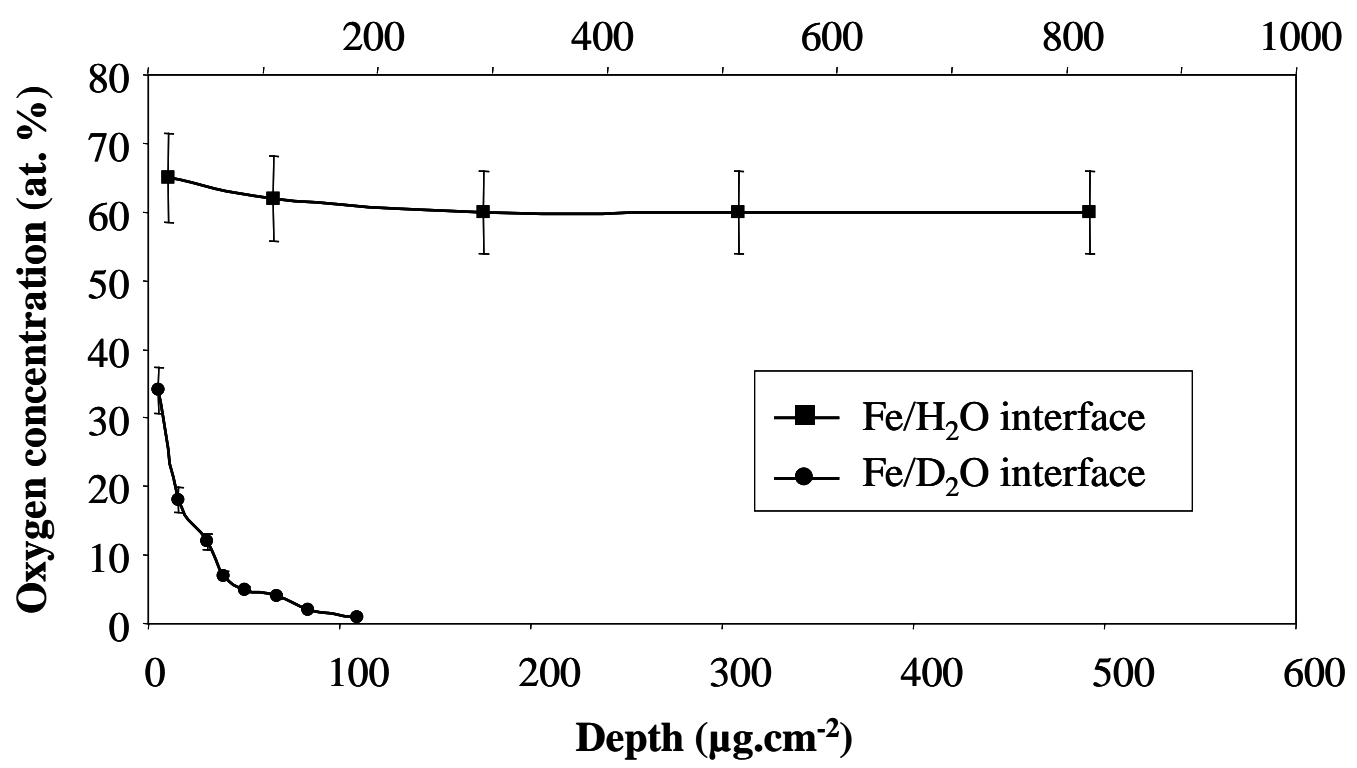


Figure 4

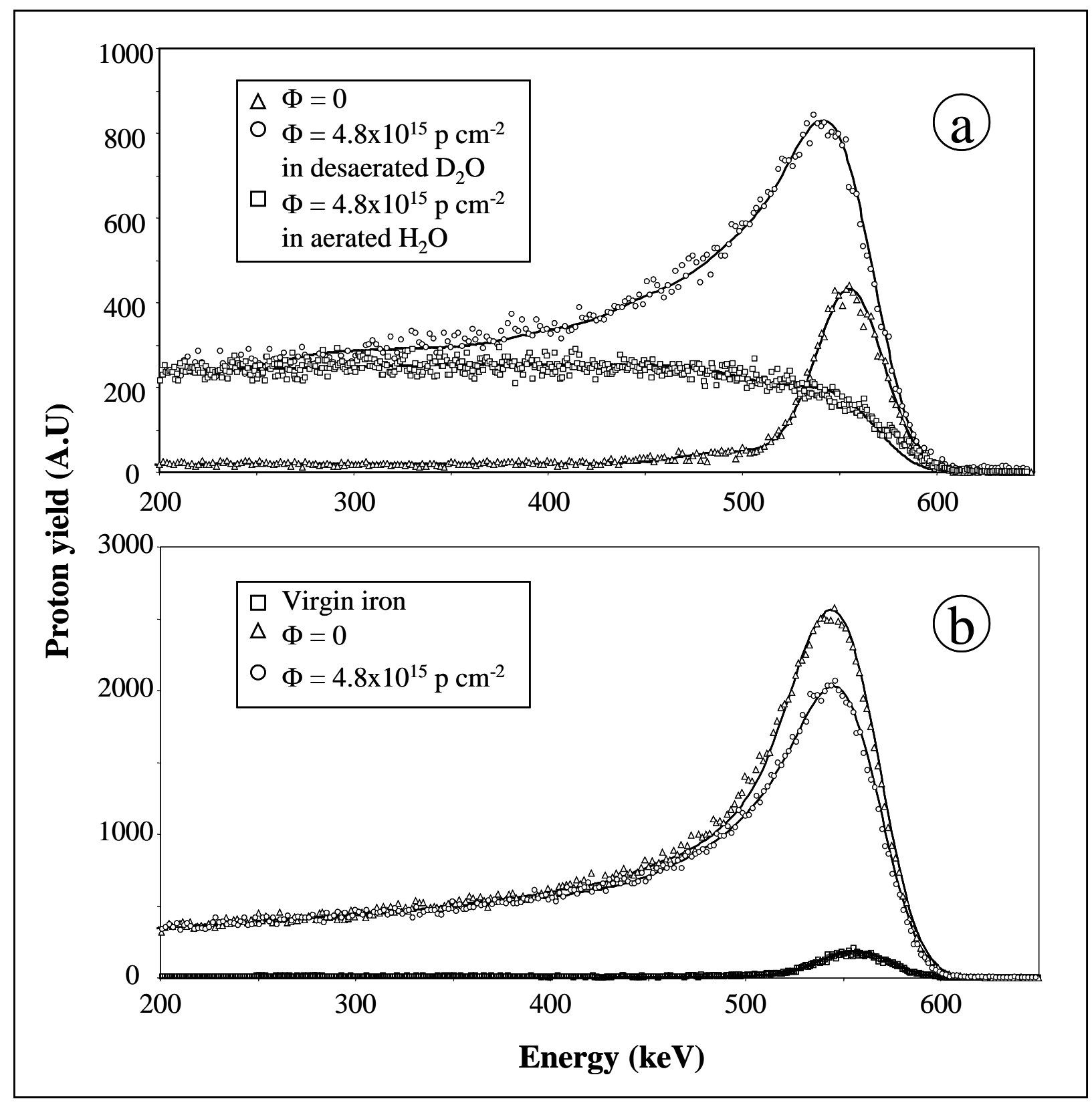


Figure 5

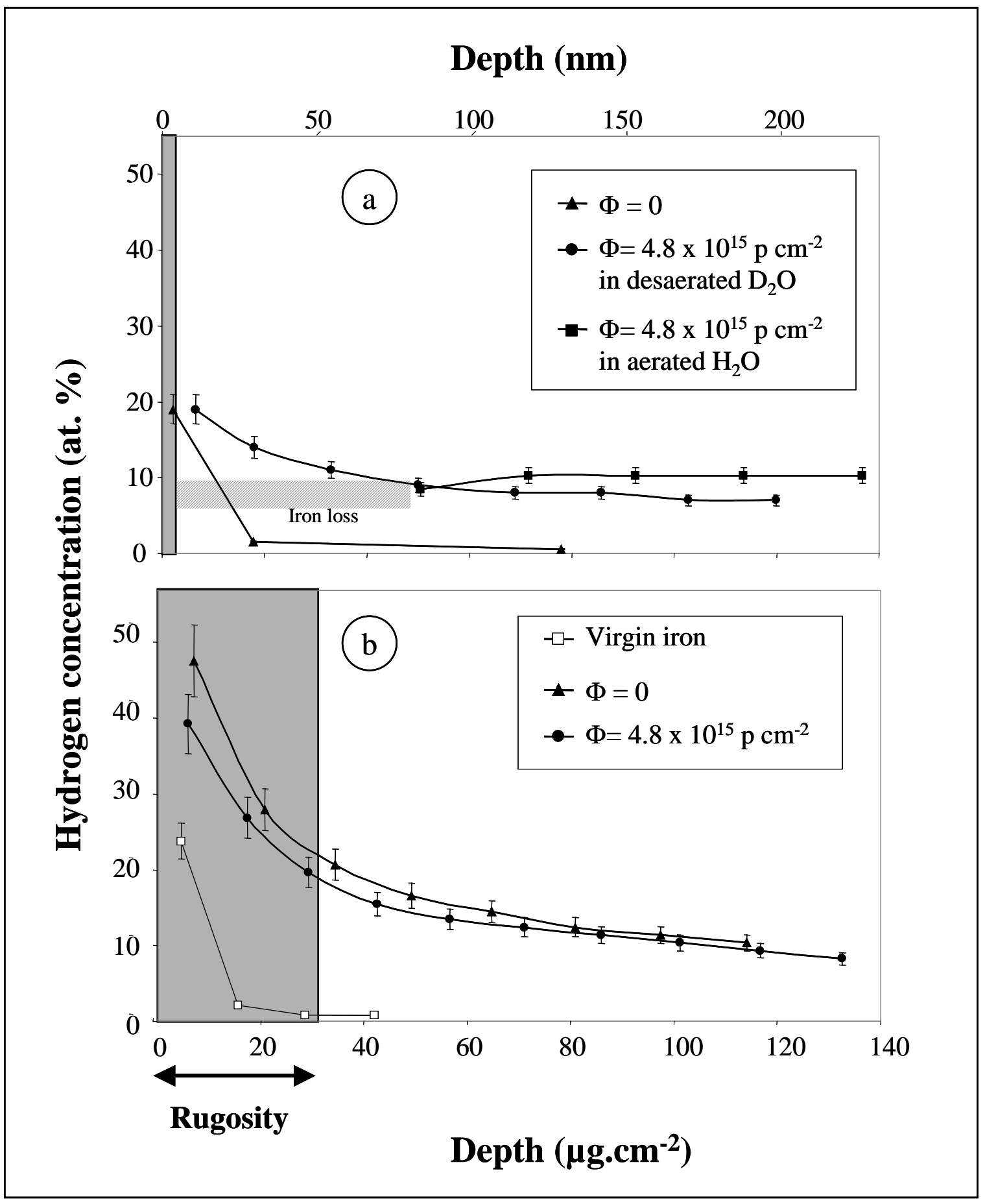


Figure 6

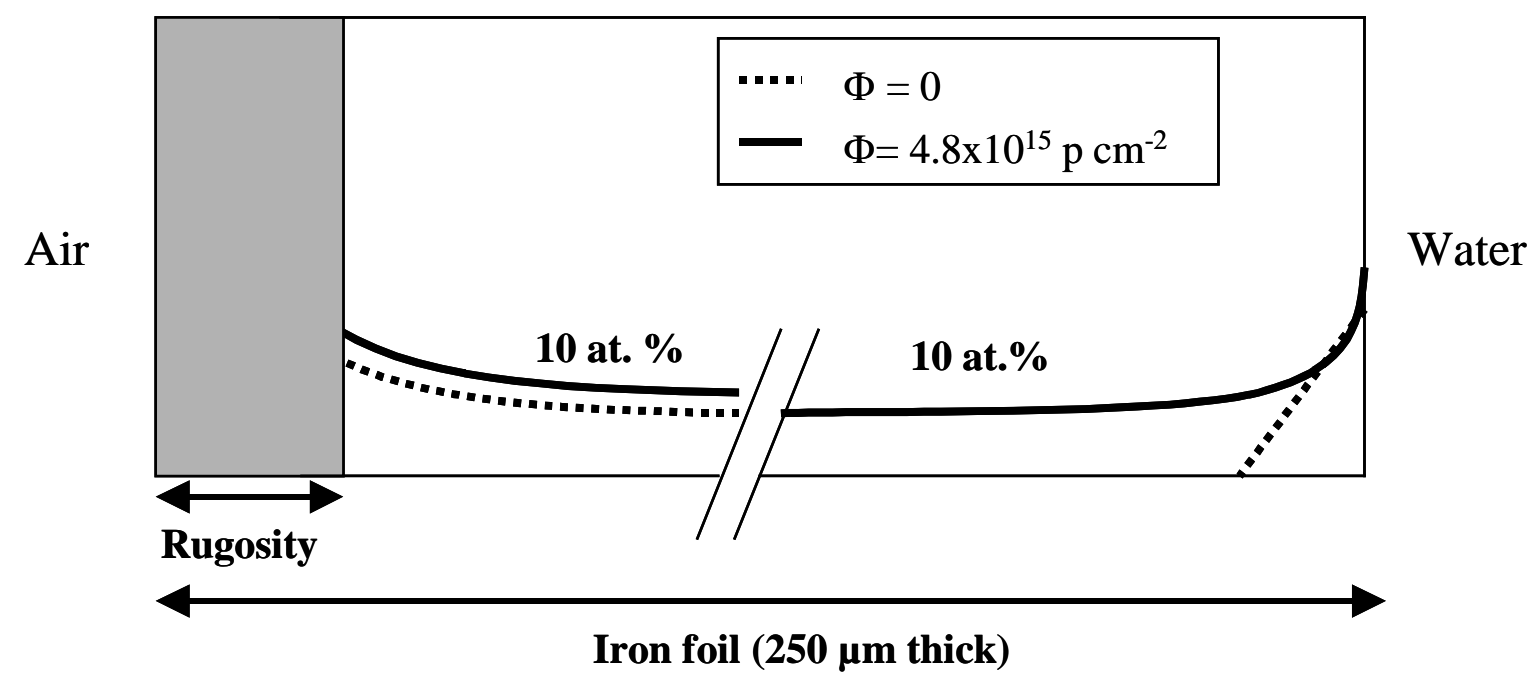

